\title{
Clinical and Microbiological Profile of Various Microorganisms Causing Keratitis in a Tertiary Care Hospital, Jaipur, India
}

\author{
Swati Gupta* and Suman Rishi \\ Department Microbiology, National Institute of Medical Sciences and Research, \\ Jaipur, Rajasthan 3030121, India \\ *Corresponding author
}

\section{A B S T R A C T}

\section{Ke y w ords \\ Keratitis, \\ Microbiological \\ Profile, \\ $\mathrm{KOH}$ mount. \\ Article Info \\ Accepted: \\ 22 January 2017 \\ Available Online: \\ 10 February 2017}

The aim of this study is to isolate and identify the various organisms from cases of infective keratitis obtained from the department of ophthalmology in our college. Ninety six numbers of cases were included in this study, in the duration period of 18 months i.e. from January 2015 to June 2016. The corneal scrapings were processed by bacterial and fungal culture methods and microscopic examination by Gram's stain and $\mathrm{KOH}$ mount. Bacterial isolates were identified by standard biochemical methods. Our study showed higher prevalence of fungal keratitis i.e. 37 (56.9\%) in comparison to bacterial keratitis $28(43.1 \%)$.

\section{Introduction}

The cornea is the anterior part of the eye covering the pupil. It is the most efficient and first refracting surface of the eye. The healthy cornea is deprived of both vascular and lymphatic channels. Infective keratitis is a common and dreadful ocular infection of the cornea by infective organisms like bacteria, fungi, virus or parasite (O’Brien, 1997). Its main clinical presentation is corneal ulcer that is defined as a loss of corneal epithelium with infiltration and suppuration of underlying stroma accompanied with signs of inflammation with or without hypopyon.

In 1869 "James Wardop" had introduced the term keratitis in his essay on morbid anatomy of human eye (James). According to world health organization (WHO), it has been said that in today's world the second most common cause of vision loss and blindness is corneal disease, next only to cataract.

In India, corneal blindness accounts around 6.8 million people suffering with vision less than 20/200 in at least one eye and of these, almost a million have bilateral corneal blindness (Shrinivasan, 2007). In year 20062007 national survey was conducted by the government of India who found that in our country $0.90 \%$ of total blindness is as a result of corneal lesion. It is also expected that by 2020 this number of corneal blind people in India will escalate to 10.6 million (Lim, 1997). All over the world, bacterial keratitis is the preeminent cause of keratitis followed by fungal keratitis but vice versa occurs in case 
of India and other tropical countries. Moreover, in developing countries bacteria has been replaced by fungus as the paramount cause of infectious keratitis (Sabysachisengupta et al., 2011).

There are large regional differences in the relative prevalence of each of the causative organism determined by geographical distribution, climate and socioeconomic factors. In tropical countries like India due to large agrarian population and environmental factors, fungal corneal infection is the main intruder of the cornea (Verenkar et al., 1998) and is often associated with accidental trauma with vegetative matter.

In temperate climate of UK the most common causes are acanthamoeba, fungus and microsporidium whereas in Northern part of United State of America, the incidence of mycotic keratitis is very low (Parisa et al., 2013). In sub tropical countries of the third world, more than $50 \%$ of keratitis falls under fungal keratitis.

In 1879Professor Theodor Leber from Germany first time described fungal keratitis (Nitin Goel Insan et al., 2013). Since then, there is a drastic rise in the number of fungal keratitis cases. As many as 70 species of fungi can cause Keratomycosis, which is divided into three categories.

\section{Causative fungal organisms}

\section{Filamentous fungi}

Pigmented also known as dematiaceous, which clinically or on culture media produce characteristic black/brown pigment.

Cladosporium species, Botryodiploidia species, Curvularia species, Bipolaris species, Exserohilum species, Alternaria species. Non pigmented also known as monilaceous which do not produce such pigments. Fusarium, Aspergillus, Mucor species, Acremonium species, Pseudoallescheria boydii, Rhizopus species and Penicillium species.

\section{Yeast like}

Candida albicans and Non Candida albicans.

\section{Dimorphic fungi}

Blastomyces and Cryptococcus etc.

\section{Causative bacterial organism}

Staphylococcus aureus, Coagulase negative Staphylococcus, Streptococcus, Corynebacterium diphtheria, Pseudomonas, Enterobacter, Hemophillus influenza, Moraxella, N. gonorrhea

Viral causes of keratitis are Herpes simplex, Herpes zoster and other Adenovirus infection etc., out of these most common is Herpes simplex which will often lead to blindness.

Initially bacterial keratitis was of two types non purulent and purulent. Example of non purulent corneal ulcers is diplobacilli and example of purulent corneal ulcers is Pneumococci, Staphylococci, Streptococci etc.

The first purulent corneal ulcer was reported by Gasparrini in 1893 in his paper published "Significance of the Pneumococcus in ophthalmology in which he had cultivated the Pneumococuus from several cases of hypopyon keratitis. In the earliest research no bacteria were isolated, as highly susceptible Pneumococci can only be demonstrated under selective conditions.

\section{Materials and Methods}

Corneal scrapings from 96 patients with the 
clinical diagnosis of corneal ulcer with or without hypopyon attending ophthalmology department of NIMS Hospital from January 2015 to June 2016 were included in the study.

History: Proper history was taken like age, sex, occupation, H/O trauma, surgery, antibiotic intake, steroid intake. Consent was taken for corneal scrapping.

Sample collection: Corneal scrapping was taken in ophthalmology department under local anesthesia i.e. $4 \%$ paracaine eye drops without preservative.

Corneal scrapping is done from the leading edge and the base of the ulcer by using kimura spatula or 15 no sterile Bard Parker Surgical Blade with the help of slit lamp under aseptic conditions

One sample is collected which is divided into four. Two samples were used for microscopy i.e. $\mathrm{KOH}$ and Gram's and the other two were used for fungal (SDA) and bacterial culture (Blood Agar).

Culture: Inoculated SDA, Blood agar and slides were labeled and transported to microbiology laboratory, where SDA and Blood agar was incubated at $25^{\circ} \mathrm{C}$ and $37^{\circ} \mathrm{C}$ respectively in the incubator.

Biochemical test: Various types of test were performed for identification of organism causing keratitis. Catalase followed by coagulase test was done to identify Gram positive cocci. Oxidase test, indole test, methyl red, Voges-Proskauer, urease production test, citrate utilization test, triple sugar iron test were done to identify Gram negative bacilli.

LPCB mount: Lactose phenol cotton blue mount was prepared from growth on SDA for morphological identification of organism causing keratitis.

\section{Results and Discussion}

96 patients were enrolled in 18 months of duration from January 2015 to June 2016. These patients presented in ophthalmology OPD of National Institute of Medical Science and Research, NIMS University, Jaipur with complaints of painful diminution of vision.

Out of 96 patients, 67 were male and 29 were females with a ratio of male to female with corneal ulceration 2.3:1.

Patient's age group ranged from 5years to 80 years. 2 patients belonged to group $<10$ years, 2 were under age group of 11- 20 years, 10 under the age of 21-30 years of age group, 22 patients were falling under age group of 31-40years, 28 were in 41-50 years, 17 fell in 51-60 years, 10 fell between 61-70 years and 5 fell in $>70$ years (Figure 1).

Table 1 shows that most common predisposing factor for bacterial keratitis was trauma with foreign body i.e 6 followed by 5 post ocular surgery, 4 trauma with plant and $\mathrm{H} / \mathrm{O}$ long term antibiotics intake, $3 \mathrm{H} / \mathrm{O}$ contact lens wear, $2 \mathrm{H} / \mathrm{O}$ conjunctivitis and Diabetes Mellitus and $1 \mathrm{H} / \mathrm{O}$ long term steroids intake and dacrocystitis. Whereas for fungal keratitis most common predisposing factor was trauma with plant 25 , followed by trauma with foreign body 11 and $\mathrm{H} / \mathrm{O}$ of diabetes mellitus.

Figure 2 shows that out of 96 samples 65 i.e. $68 \%$ were culture positive where as $31(32 \%)$ were negative on culture

Out of these 65 culture positive cases 28 $(43.1 \%)$ were positive for bacterial culture and remaining $37(56.9 \%)$ were positive for fungal culture (Table 2).

In Gram's staining of 96 cases of corneal ulcer, 17 were showing bacteria whereas 28 
were grown on culture. As per this study culture is the best method for isolation of both bacterial as well as fungal isolation (Table 3 ).

Table 4 showed that out of 96 samples 37 were positive on fungal culture, 11 were positive on Gram staining and 16 were showing hyphae on $\mathrm{KOH}$ mount.

Total 28 bacteria and 37 fungi were isolated by culture. Out of these 28 isolated bacteria the most common was Staphylococcus aureus i.e. $57.3 \%$ (16) followed by $32.2 \%(9)$ Pseudomonas spp., 7\% (2) coagulase negative Staphylococcus and 3.5\% (1) were Klebsiella spp. (Table 5).

Out of 37 isolated fungi most common was Aspergillus spp. 62.2\% (23), followed by
$24.3 \%$ (9) Fusarium spp., $10.8 \% \quad$ (4) Curvularia spp. and 2.7\% (1) was Candida albicans (Figure 3).

Though the problem of blindness is universal but the degree is much more in India i.e. 1/4th of the world's total blind population. Worldwide corneal infections are the ruling cause of ocular morbidity and blindness. In India also major cause of blindness is corneal ulcers. According to $\mathrm{WHO}$, corneal blindness is responsible for $0.90 \%$ of overall blindness in India. Corneal blindness is the major consequences of infectious keratitis followed by corneal dystrophy. Microorganisms including bacteria, fungi, viruses and parasites are the major cause of infectious keratitis.

Table.1 Predisposing factors for different organisms

\begin{tabular}{|l|c|c|c|}
\hline Predisposition Factor & Bacteria & Fungal & None \\
\hline Trauma with plant & 4 & 25 & 12 \\
\hline Trauma with foreign body & 6 & 11 & 16 \\
\hline H/o Diabetes mellitus & 2 & 1 & 0 \\
\hline H/O Contact lens wear & 3 & 0 & 0 \\
\hline H/O Steroids intake & 1 & 0 & 1 \\
\hline H/O Antibiotic intake & 4 & 0 & 0 \\
\hline Post ocular surgery & 5 & 0 & 0 \\
\hline Conjuctivitis & 2 & 0 & 0 \\
\hline Dacrocystitis & 1 & 0 & 0 \\
\hline None & 0 & 0 & 2 \\
\hline TOTAL & 28 & 37 & 31 \\
\hline
\end{tabular}

Table.2 Distribution of cases by causative organism

\begin{tabular}{|l|l|l|}
\hline Organism & Number & Percentage(\%) \\
\hline Bacteria & 28 & 43.1 \\
\hline Fungus & 37 & 56.9 \\
\hline Total & 65 & 100 \\
\hline
\end{tabular}


Table.3 Detection of positive bacterial cases by different method

\begin{tabular}{|l|l|l|l|}
\hline Diagnostic method & Positive & Negative & Total \\
\hline Gram stain & 17 & 79 & 96 \\
\hline Culture & 28 & 68 & 96 \\
\hline
\end{tabular}

Table.4 Detection of positive fungal cases by different method

\begin{tabular}{|l|l|l|l|}
\hline Diagnostic method & Positive & Negative & Total \\
\hline KOH & 16 & 80 & 96 \\
\hline Gram & 11 & 85 & 96 \\
\hline Culture & 37 & 59 & 96 \\
\hline
\end{tabular}

Table.5 Distribution of cases by different type of bacteria

\begin{tabular}{|l|c|c|}
\hline Type of Bacteria & Number & Percentage (\%) \\
\hline Staphylococcus aureus & 16 & 57.3 \\
\hline Coagulase Negative Staphylococcus & 02 & 7.0 \\
\hline Pseudomonas spp. & 09 & 32.2 \\
\hline Klebsiella spp. & 01 & 3.5 \\
\hline TOTAL & 28 & 100 \\
\hline
\end{tabular}

Clinical picture showing keratitis Corneal ulcer under slit lamp examination
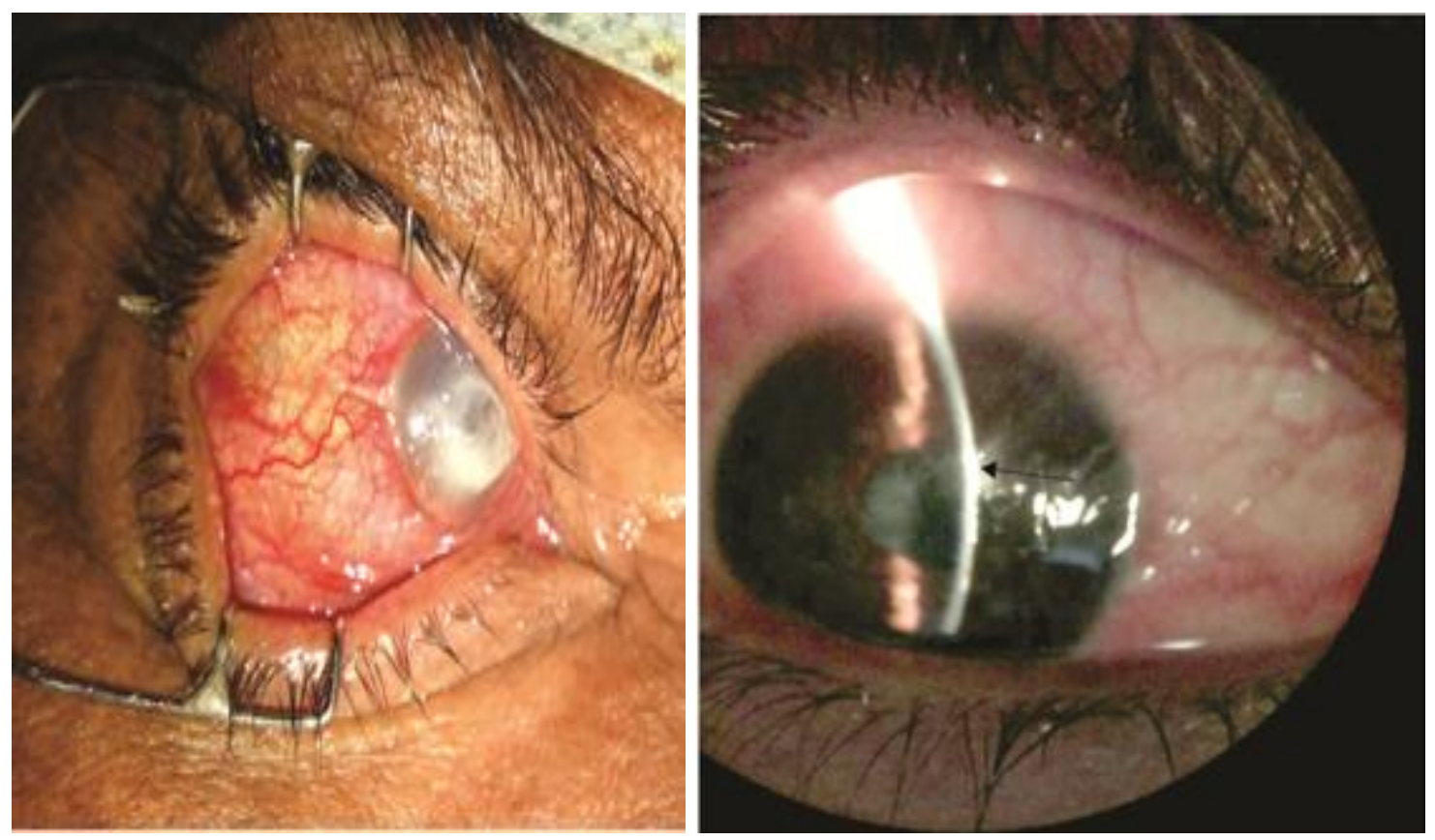
C pattern Streaking on blood agar C pattern streaking on SDA showing Aspergillus
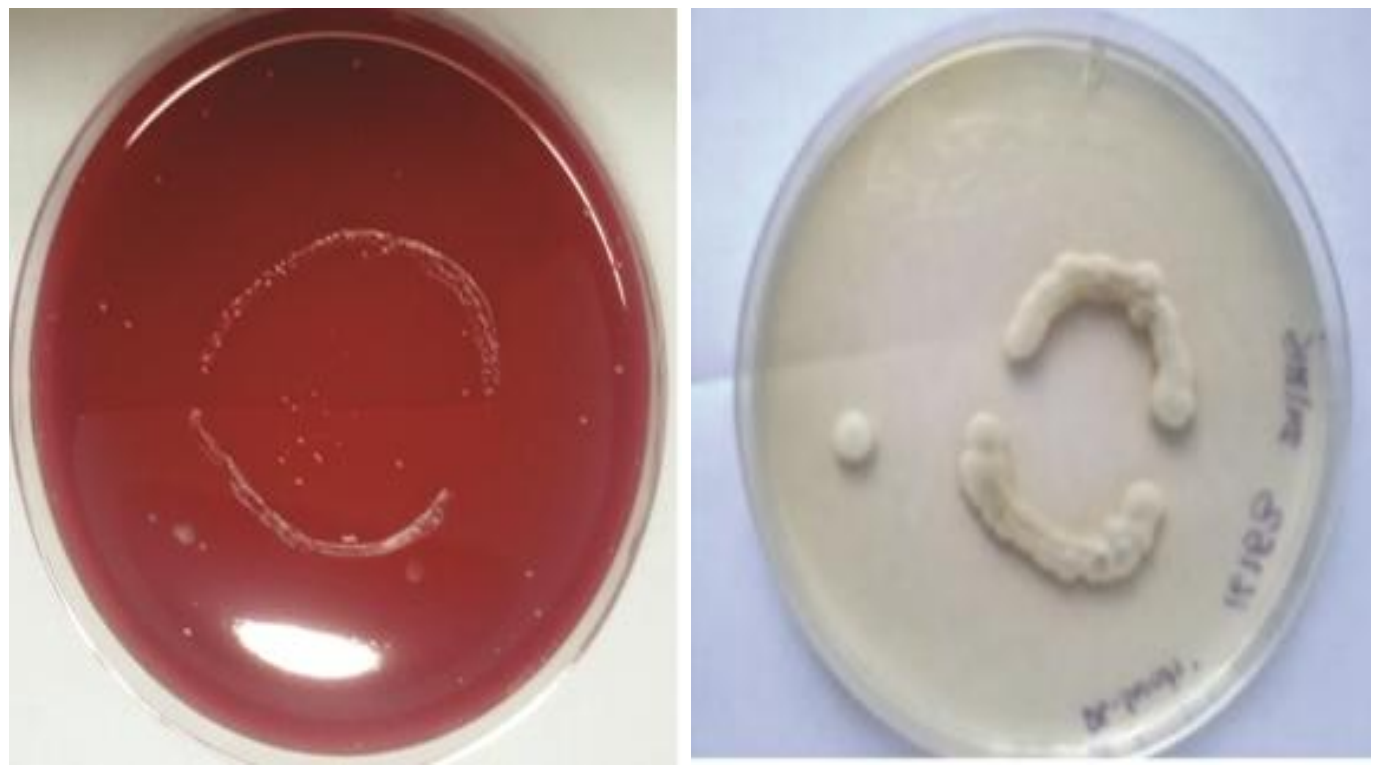

LPCB showing Fusarium spp. SDA showing growth of Fusarium spp.
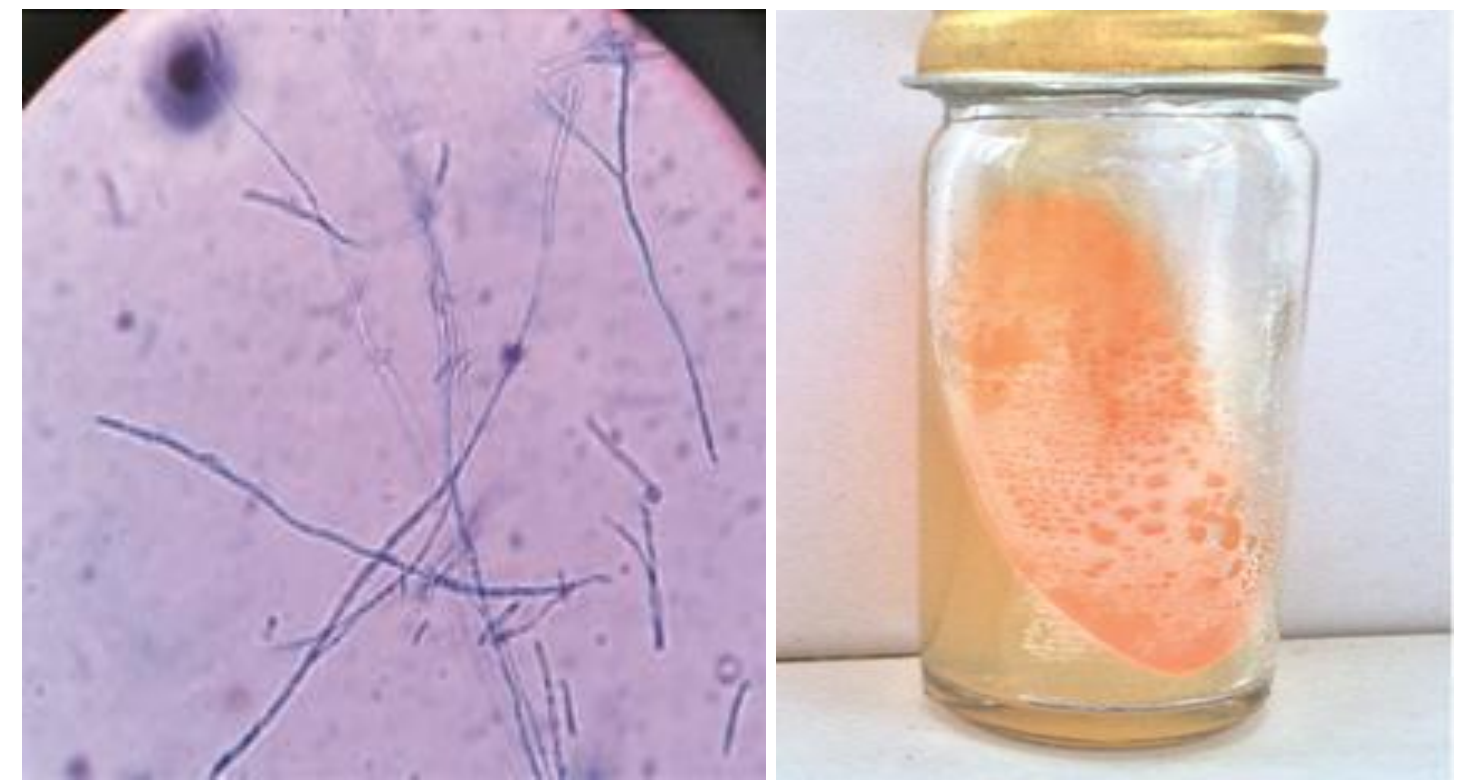
Figure.1 Distribution of patients according to age

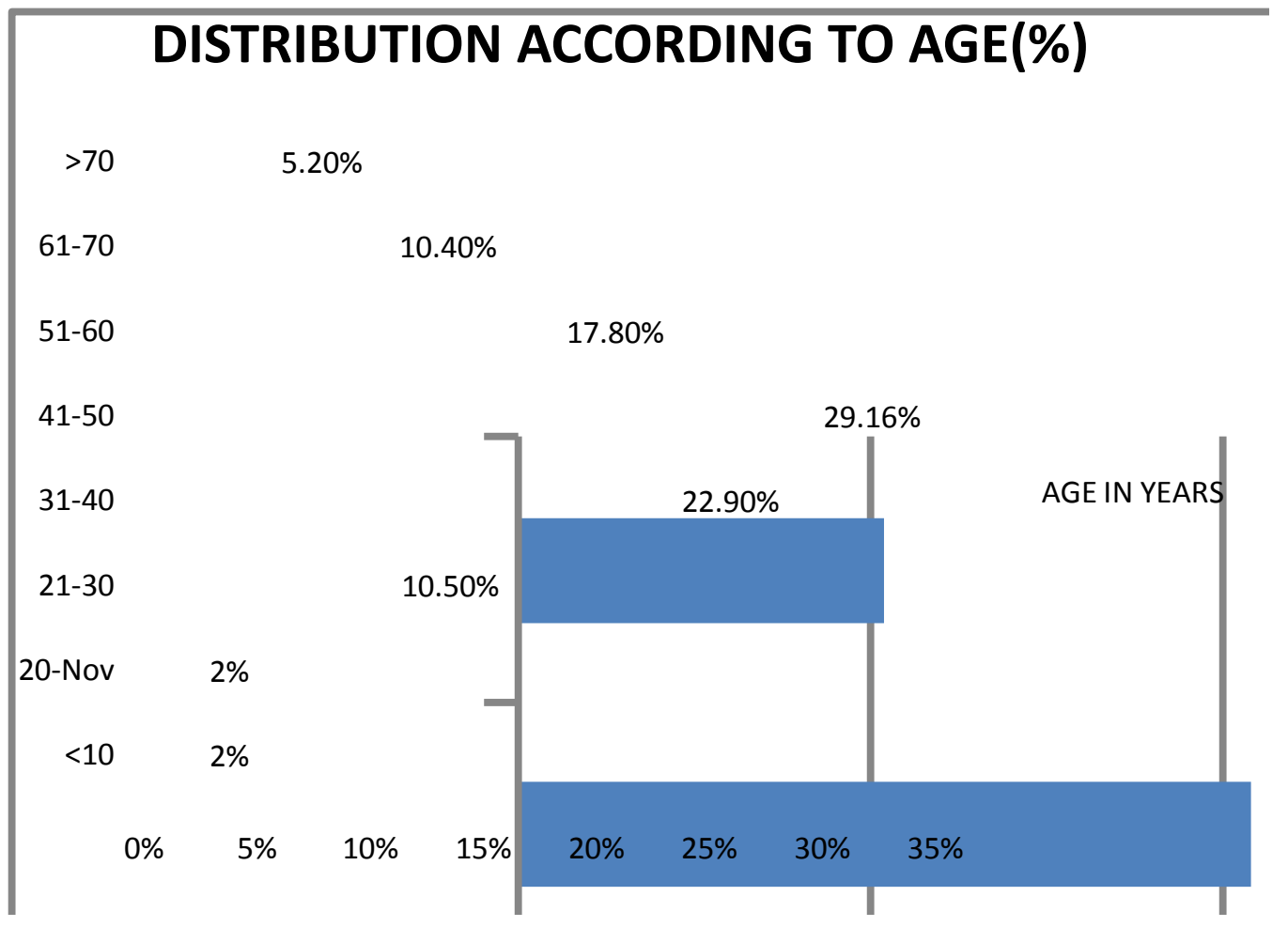

Figure.2 Distribution of cases on the basis of culture positive

\section{DISTRIBUTION ACCORDING TO GROWTH IN CULTURE(\%)}

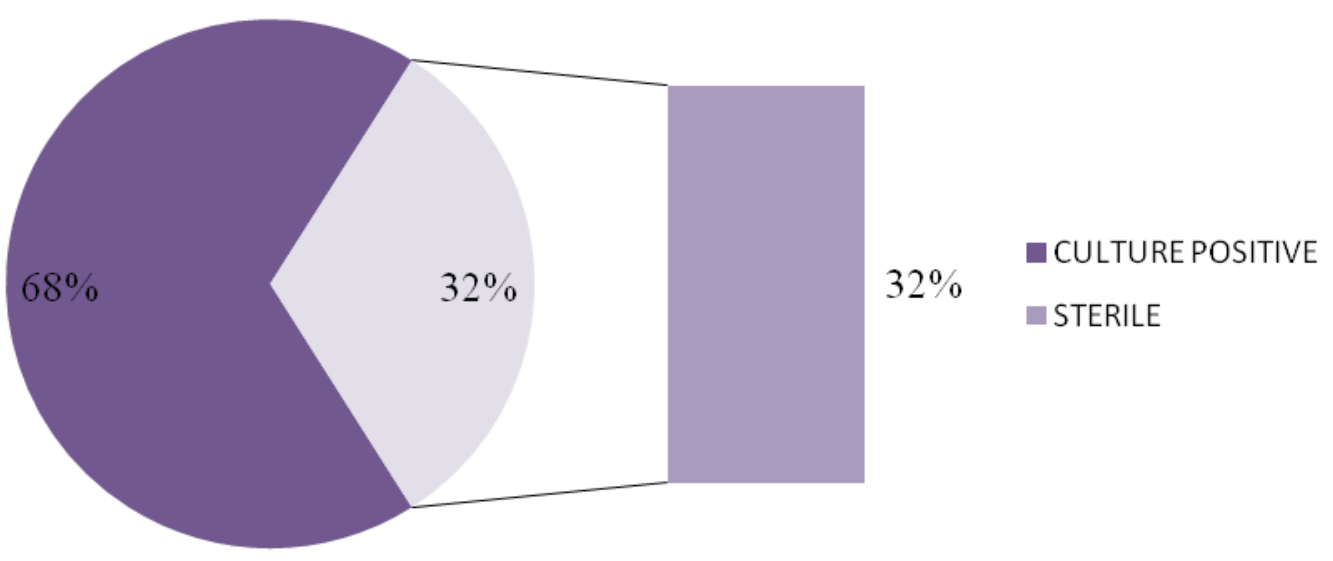


Figure.3 Distribution of cases by different types of fungi

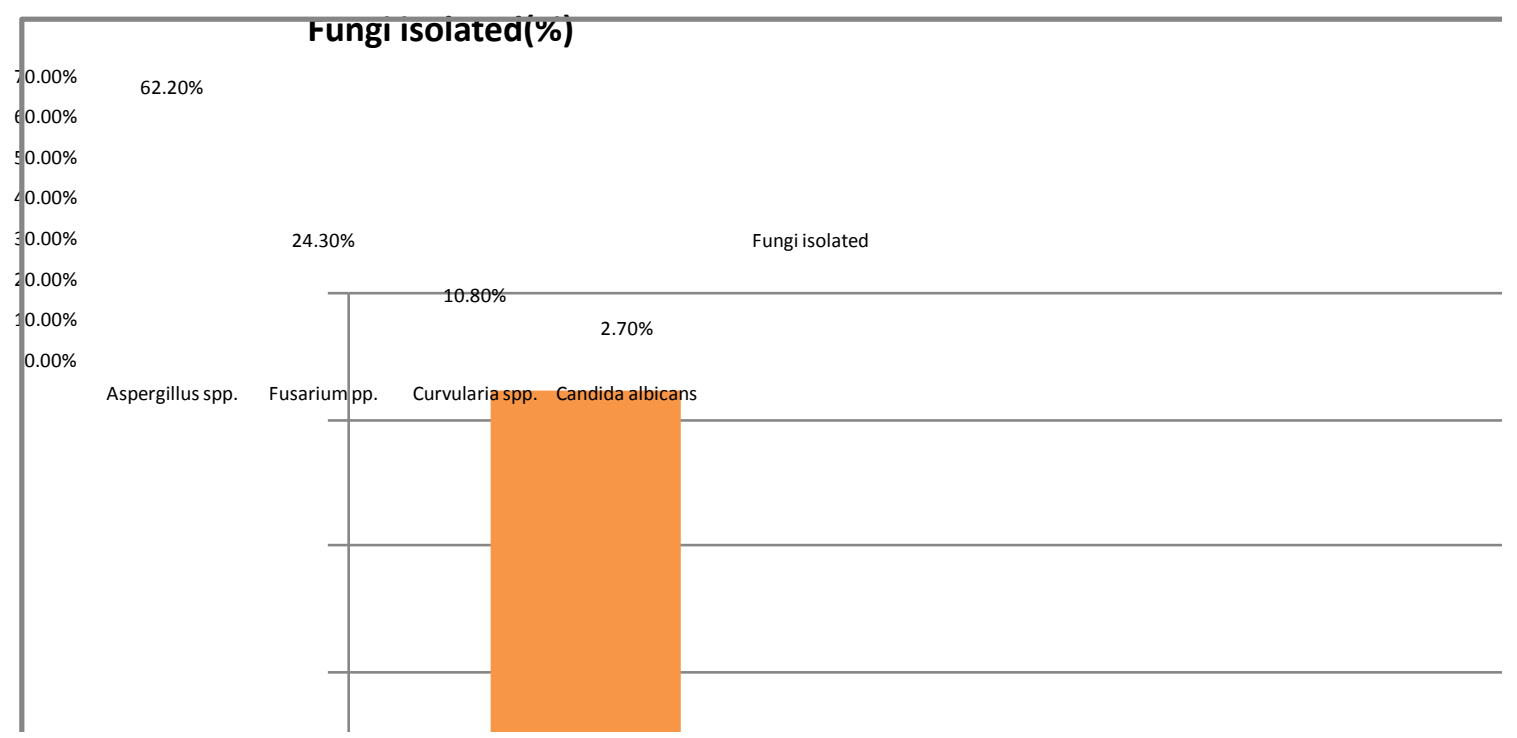

In our study out of 96 cases, 65(68\%) cases were culture positive out of which $37(38.7 \%)$ were positive for fungal culture and 28 (29.3\%) were positive for bacterial culture. Similar fungal predominance was shown by Sirisha et al., (2015) in 2015 who concluded that fungal corneal ulcer (49\%) is more common than bacterial corneal ulcer $(21 \%)$, Suryawanshi Gaurav et al., (2013) in Maharastra found that out of 62 cases of corneal ulcer $22(35.48 \%)$ were having fungi as causative agent, $20(32.25 \%)$ were having bacteria as causative agent and $11(17.74 \%)$ were having mixed growth.

The most common bacteria isolated in our study was Staphylococcus aureus i.e. 16 (57.3\%) followed by 9 (32.2\%) Pseudomonas spp., 2 (7\%) CONS and 1 (3.5\%) Klebsiella spp. Our study is in accordance with the studies done by Suryawanshi Gaurav et al., (2013) who isolated $12 \quad$ (38.7\%) Staphylococcus aureus as most common pathogenic bacteria followed by $8(25.8 \%)$ Streptococcus pneumoniae, 6 (19.35\%) Pseudomonas spp. Filamentous fungi are the major fungal pathogens in fungal corneal ulcer. Yeast like fungi have low preponderance in fungal corneal ulcer. In our study out of all 37 cultivated fungi, 36 were filamentous fungi and only 1 was yeast like fungi. Most common isolated fungi was hyaline fungi $(\mathrm{n}=32)$ including Aspergillus spp. (62.2\%) and Fusarium spp. (24.3\%). They were followed by phaeiod fungi. Aspergillus spp. was most predominant in fungal corneal ulcer as shown by other studies in the Indian subcontinent $61.53 \%$ in Manglore by Sangeev et al., (2012), 41.18\% in Chandigarh by Jagdish Chander et al., (2008), 48.48\% in Maharashtra by Suryawanshi Gaurav et al., (2013).

Unlike our study Fusarium spp. have been reported as the major causative agent of fungal corneal ulcer in Vishakapatnum by Sirisha et al., (2015) who reported that out of 52 fungal cornel ulcer patients, 19 (36.54\%) were positive for Fusarium spp. Amrutha Kumari et al., (2014) in Karnataka also stated Fusarium (61.91\%) as the most common fungi isolated from corneal ulcer.

As per our study fungi is more predominant causative agent of keratitis than bacteria. Hence it should be kept in mind before 
treating the patient that to find an appropriate causative organism we should always go for $\mathrm{KOH}$ mount, Gram stain and culture so that an appropriate treatment can be prescribed, as it is a preventable cause of blindness affecting large number of people worldwide. Our one step towards the identification can prevent someone from becoming disabled.

\section{Acknowledgement}

I would like to thank my teachers, my family and my whole department for their guidance and extended help in completion of my research work.

\section{References}

Amrutha Kumari, B., D. Venkatesha. 2014. Microbiological profile of Ulcerative Keratitis in a tertiary care hospital. Int. J. Res. Health Sci., 2(2): 599-603.

Bharathi, M.J., R. Ramakrishnan, S. Vasu, R. Meenakshi, and R. Palaniappan. 2002. In vitro efficacy of antibacterials against bacterial isolates from corneal ulcers. Indian J. Ophthalmol., 50(2): 109-114.

Geethakumari, P.V., Remya, R., Girijadevi, M.S., Reena, A. 2011. Bacterial Keratitis and Fungal Keratitis in South Kerala: A Comparative Study. KJO, Pp. 43-46.

Jagdish Chander, Nidhi Singhla, Nalini Agnihotri, Sudesh Kumar Arya, Antariksh Deep. 2008. Keratomycosis in and around Chandigarh: A five year study from a north Indian tertiary care Hospital. Indian J. Pathol. Microbiol., 51(2): 304-306.

James Wardop. Anatomy of human eye: From Medical Mycology by Chester W. Emmons, 2nd Edition.

Kent, W., Small, Candy, K. 2014. Chan, Rosemary Silva-Garcia, Thomas J Wash. Onset of an outbreak of biopolarishawaiiensis fungal endopthalmitis after intraviteral of triamcinolone. Ophthalmol., 121(4): 952.

Leck, A.K., P.A. Thomas, M., Hagan et al., Etiology of suppurative corneal ulcers in ghana and south india and epidemiology of fungal keratitis. The British J. Ophthalmol., 86(11): 12111215.

Lim, A.S. 1997. Mass blindness has shifted from infection (onchocerciasis, trachoma, corneal ulcers) to cataract. Ophthalmol., 211: 270.

McDonnel, P.J., Nobe, J., Gauderman, W.J., et al., 1992. Community care of corneal ulcers. Am. J. Ophthalmol., 114: 531538.

Nitin Goel Insan, Vijay Mane, B.L. Chaudhary, Mahesh Singh Danu, Amodyadav and Vivek Srivastava. 2013. A review of fungal keratitis. A review of fungal keratitis: etiology and laboratory diagnosis. Int. J. Curr. Microbiol. Appl. Sci., 2(6): 307-314.

O’Brien, T.P. 1997. Bacterial keratitis, Chapter 94. In: Cornea: Cornea and External Diseases, Clinical Diagnosis and Management. St. Louis, Mosby book. vol. II, 1139-1189.

Parisa Badiee, Jundishal. 2013. Mycotic keratitis, a state of the art review. $J$. Microbiol., 6(5).

Sabysachisengupta, sanjeevanirajan, padmattiravindernath reddy, K., Thiruvengada, R.D ravindaran, P. lalitha, C.M. Vatilingam. 2011. Comparative study on the incidence and outcomes of pigmented versus non pigmented Keratomycosis. Indian $J$. Opthalmol., Volume 59 No. 4 pp.291296.

Sanjeev, H., Karnaker Vimal, K., Pai Vijay, Pai Asha, K.B. 2012. Fungal profile of infectious keratitis in a tertiary care hospital - our experience. Nitte 
University J. Health Sci., vol.2, No 2.10-14.

Shrinivasan, M. 2007. Infective keratitis: a challenge to Indian ophthalmologists. Indian J. Ophthalmol., 55(1): 5-6.

Sirisha, T., Jayalakshmi, L., Ratnakumari, G., Viswamitra, P. 2015. Microbiological Profile and Their Antimicrobial Susceptibility in Infective Keratitis at Regional Eye Hospital, Visakhapatnam. Scholars J. Appl. Med. Sci., 3(3A): 1083-1088
Suryawanshi Gaurav, S., Khindria Ashish. 2013. Clinical Studyof Causative Microbial AgentsofSuppurative Keratitis Casesin Rural Area. Int. J. Med. Res. Health Sci., Volume 2 Issue $1 ; 59-62$.

Verenkar, M.P., Subhangi, B., Pinto, M.J.W. 1998. A study of mycotic keratitis in goa. IJMM, 16: 58-60.

\section{How to cite this article:}

Swati Gupta and Suman Rishi. 2017. Clinical and Microbiological Profile of Various Microorganisms Causing Keratitis in a Tertiary Care Hospital, Jaipur. Int.J.Curr.Microbiol.App.Sci. 6(2): 1333-1342. doi: http://dx.doi.org/10.20546/ijcmas.2017.602.151 